\title{
Genome-scale transcriptional analysis reveals key genes associated with the development of type II diabetes in mice
}

\author{
YUCHI ZHANG $^{1 *}$, DONGWEI HAN ${ }^{1 *}$, PENGYANG YU ${ }^{1}$, QIJING HUANG ${ }^{1}$ and PENGLING GE ${ }^{1,2}$ \\ ${ }^{1}$ Department of Pharmacology, School of Basic Medical Sciences, Heilongjiang University of Chinese Medicine, \\ Harbin, Heilongjiang 150040; ${ }^{2}$ The Key Laboratory of Myocardial Ischemia, Harbin Medical University \\ of Chinese Ministry of Education, Harbin, Heilongjiang 150086, P.R. China
}

Received September 22, 2015; Accepted November 9, 2016

DOI: $10.3892 / \mathrm{etm} .2017 .4042$

\begin{abstract}
Diabetes mellitus is one of the primary diseases that pose a threat to human health. The focus of the present study is type II diabetes (T2D), which is caused by obesity and is the most prevalent type of diabetes. However, genome-scale transcriptional analysis of diabetic liver in the development process of T2D is yet to be further elucidated. Microassays were performed on liver tissue samples from three-, six- and nine-week-old $d b / d b$ mice with diabetes and $d b / m$ mice to investigate differentially expressed mRNA. Based on the results of genome-scale transcriptional analysis, five genes were screened in the present study: chromobox 8 (CBX8), de-etiolated homolog 1 and damage specific DNA binding protein 1 associated 1 (DDA1), Phosphoinositide-3-kinase regulatory subunit $6(P I K 3 R 6)$, WD repeat domain 41 (WDR41) and Glycine Amidinotransferase (GATM). At three weeks of age, no significant differences in levels or ratios of expression were observed. However, at six and nine weeks, expression of $C B X 8, D D A 1, P I K 3 R 6$ and WDR41 was significantly upregulated $(\mathrm{P}<0.05)$ in the $d b / d b$ model group compared with the control group, whereas GATM expression was significantly downregulated $(\mathrm{P}<0.05)$. These results suggest that T2D-related differential expression of genes becomes more marked with age, which was confirmed via reverse transcription-quantitative polymerase chain reaction. Genome-scale transcriptional analysis in diabetic mice provided a novel insight into the molecular. events associated with the role of mRNAs in T2D development, with specific emphasis upon CBX8,DDA1, PIK3R6, GATM and WDR41. The results of the present study may provide rationale for the
\end{abstract}

Correspondence to: Professor Pengling Ge, Department of Pharmacology, School of Basic Medical Sciences, Heilongjiang University of Chinese Medicine, 24 Heping Road, Harbin, Heilongjiang 150040, P.R. China

E-mail: penglingge@126.com

*Contributed equally

Key words: type II diabetes, mRNA, gene expression, microarray investigation of the target genes of these mRNAs in future studies.

\section{Introduction}

Modern lifestyle changes, such as an increased prevalence of high-calorie diets and low levels of physical activity have lead to obesity becoming a global pandemic (1). Obesity may lead to insulin resistance (IR), which in turn may lead to diabetes (2). Type II diabetes (T2D), which is caused by chronic IR and loss of functional islet $\beta$-cells is now one of the most prevalent types of diabetes $(3,4)$. In humans and animal models, obesity has been shown to be a major causative factor in the development of IR (2), which is typically associated with dysfunctional metabolism and leads to increased intracellular fat content in liver (5). The liver serves a key role in energy metabolism, as does IR. Therefore, analyzing the changes in gene expression profiles of the liver may elucidate the process by which T2D develops.

However, the underlying molecular mechanisms remain to be determined (6). The identification of a suitable model animal is critical for the study of T2D (6). The $d b / d b$ mouse is one of the best animal models for the study of human T2D as some of its phenotypes, including polyuria, hyperglycemia and glucosuria, are similar to those observed in human patients with T2D. Db/db mice were discovered by Hummel et al in the inbred line of C57BLKS/J (BKS) in 1966, which is caused by mutations in the gene of leptin receptor (Lepr) gene located in mouse chromosome 4 (7). In $d b / d b$ mice this typically presents as a hypothalamic defect; wherein satiety is not produced due to a lack of the satiety substance (leptin), lack of reaction to anabolic greater than catabolism, and gradually develop severe T2D accompanied by hyperglycemia due to the accumulation of fat (8) Mice and humans with T2D exhibit similar clinical symptoms, such as polydipsia, polyphagia, urorrhagia, obesity, hyperglycemia, hyperglycemia, IR and lipid metabolism abnormality (9). Using the $d b / d b$ mice model, it may be possible to investigate the underlying molecular mechanisms and elucidate the complex intrinsic metabolic processes associated with T2D.

It is widely accepted that if only a single gene is mutated, the incidence of T2D is low (10). However, environmental factors may lead to the modification of DNA. When mRNA 
Table I. Primers used in reverse transcription-quantitative polymerase chain reaction.

\begin{tabular}{lll}
\hline Gene & \multicolumn{1}{c}{ Forward primer sequence } & \multicolumn{1}{c}{ Reverse primer sequence } \\
\hline$C B X 8$ & 5'-ATTCGCAAAGGACGCATGGAA-3' & 5'-CCTCGCTTTTTGGGGCCATA-3' \\
DDA1 & 5'-GGCTTGCCCGTCTACAACAA-3' & 5'-CCGCAGAAGTATGTTCGTCTTTT-3' \\
PIK3R6 & 5'-GACGCCGTGTCATCATTCC-3' & 5'-TGGTGCAGAAGGTATAAGCTCTA-3' \\
WATM & 5'GCTTCCTCCCGAAATTCCTGT-3' & 5'-CCTCTAAAGGGTCCCATTCGT-3' \\
& 5'-CAGGGCCTAGCCGAGAAAG-3' & 5'-CCAGCAGTTCAGTATAGGGGTT-3'
\end{tabular}

CBX8, chromobox 8; DDA1, de-etiolated homolog 1 and damage specific DNA binding protein 1 associated 1; PIK3R6,phosphoinositide-3-kinase regulatory subunit 6; WDR41, WD repeat domain 41; GATM, glycine amidinotransferase.

expression reaches a certain level as a result of this, the body may never recover to the normal state (11). DNA microarray technology allows for simple and precise detection of significant changes in gene expression (11); however, searching large quantities of data to identify small changes in the association between biological molecules and disease is challenging. To overcome this problem in the present study, a comprehensive analysis of differences in mRNA expression in the $d b / d b$ mice liver tissue was performed by integrating genome-scale microarray gene expression analysis with bioinformatics analysis. Several novel potential biomarkers associated with T2D were also investigated, with a view to facilitating the future development of a more in-depth study of the pathogenesis of T2D.

\section{Materials and methods}

Ethics statement. All animal protocols were approved by the Animal Experimental Ethical Committee of Heilongjiang University of Chinese Medicine (Heilongjiang, China).

Animal models. Male BKS.Cg-m+/+Leprdb/J (db/db) mice (Nanjing Biomedical Research Institute of Nanjing University,

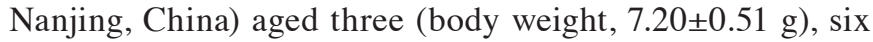
(body weight, 28.97 $\pm 0.93 \mathrm{~g}$ ) and nine weeks old (body weight, $40.27 \pm 0.63 \mathrm{~g})$ were used. Age-matched male heterozygote mice $(\mathrm{db} / \mathrm{m})$, a non-penetrant genotype (Nanjing Biomedical Research Institute of Nanjing University), were used as the control animals (three weeks old, $7.23 \pm 0.62 \mathrm{~g}$; six weeks old, $18.06 \pm 0.84 \mathrm{~g}$; nine weeks old, $23.05 \pm 0.35 \mathrm{~g}$ ). A total of 30 mice were individually housed at a constant temperature $\left(20 \pm 1^{\circ} \mathrm{C}\right)$, humidity $(50 \pm 5 \%)$ and light $(12 \mathrm{~h} /$ day $)$ conditions with a standard pellet diet and water provided ad libitum.

A total of 15 male $\mathrm{db} / \mathrm{m}$ mice were divided into three groups: Three-, six- and nine-week-old control models ( $\mathrm{n}=5$ each). Similarly, a total of 15 male $d b / d b$ mice were also divided into three groups: Three-, six- and nine-week-old model groups $(n=5$ each). All mice were weighed and sacrificed via inhaled 99\% ether (Tianjin Tianhe Chemical Co., Ltd., Tianjin China). Blood serum and livers were harvested snap frozen in liquid nitrogen and stored at $-80^{\circ} \mathrm{C}$ for further analysis.

RNA isolation and microarray profiling. Liver tissues were thawed and homogenized on ice in TRIzol (Invitrogen; Thermo Fisher Scientific, Inc., Waltham, MA, USA) and total RNA was extracted using the TRIzol kit (cat. no. 15596-026;
Invitrogen; Thermo Fisher Scientific, Inc.), according to the manufacturer's protocol. Concentration and purity of RNA were determined using the ASP-3700 spectrophotometer (ACT Gene, Inc., Piscataway, NJ, USA).

Whole-genome expression profiling was performed using Agilent mouse 4x44 K microarrays (Kang Chen Bio-Tech, Inc., Shanghai, China). Briefly, RNA samples were amplified and labeled with the Agilent One-Color RNA Spike-In Kit (cat. no. 5188-5282; Agilent Technologies, Inc., Santa Clara, CA, USA), and cRNA was hybridized to the arrays in the Agilent Hybridization Chamber (Agilent Technologies, Inc.). Hybridization and washing were performed with the Gene Expression Wash Buffer kit (cat. no. 5188-5327; Agilent Technologies, Inc.), and arrays were scanned with the GenePix 4000B microarray scanner (Molecular Devices LLC, Sunnyvale, CA, USA). Image analysis for grid alignment and the expression data was performed with Nimble Scan software (version 2.5; Roche NimbleGen, Inc., Madison, WI, USA). Volcano plots (GeneSpring Software, version 7.2; Aligent Technologies, Inc.) were used to analyze the raw data files.

Assessment of IR in the development of T2D. Fasting blood-glucose (FBG) was assayed using a blood glucose meter (Roche Diagnostics, Basel, Switzerland). Fasting insulin (FINS) was assayed using a commercially available Quantikine ELISA kit (cat. no. QC107; R\&D Systems, Inc., Minneapolis, MN, USA). The fasting insulin sensitivity index (FISI) was calculated using the following formula: FISI=ln $[1 /($ FBG $x$ FINS $)]$.

Reverse transcription-quantitative polymerase chain reaction (RT-qPCR). RT-qPCR was performed to verify gene expression microarray data. cDNA was synthesized via reverse transcription of total liver RNA using the AccuPower Rocket Script RT Premix (Bioneer Corporation, Daejeon, Korea), according to the manufacturer's protocol. Primers used for amplification are presented in Table I. Data were normalized against the expression levels of the housekeeping gene $\beta$-actin, and relative expression values were calculated using the $2^{-\Delta \Delta \mathrm{Cq}}$ method. PCR products were analyzed by agarose gel electrophoresis to ensure specificity.

Statistical analysis. Statistical data was expressed as the mean \pm standard error of the mean. Statistical significance of the differences between model groups and age-matched control 
Table II. Significantly differentially expressed genes in mice at different ages.

\begin{tabular}{|c|c|c|c|c|c|c|}
\hline \multirow[b]{2}{*}{ Gene } & \multicolumn{2}{|c|}{3 weeks old } & \multicolumn{2}{|c|}{6 weeks old } & \multicolumn{2}{|c|}{9 weeks old } \\
\hline & Fold-change & P-value & Fold-change & P-value & Fold-change & P-value \\
\hline$C B X 8$ & 2.21 & 0.0350 & 2.48 & 0.0297 & 2.71 & 0.0009 \\
\hline$D D A 1$ & 0.74 & 0.0477 & 3.37 & 0.0085 & 3.96 & 0.0009 \\
\hline PIK3R6 & 0.56 & 0.5040 & 2.1 & 0.0126 & 2.58 & 0.0317 \\
\hline GATM & -1.02 & 0.2521 & -3.89 & 0.0125 & -4.44 & 0.0077 \\
\hline WDR41 & 0.58 & 0.0713 & 4.25 & 0.0024 & 4.36 & 0.0011 \\
\hline
\end{tabular}

List of significant genes filtered where fold-change is $>2.0$ or $\leq-2.0$ and $\mathrm{P}<0.05$. $C B X 8$, chromobox $8 ; D D A 1$, de-etiolated homolog 1 and damage specific DNA binding protein 1 associated 1; PIK3R6, phosphoinositide-3-kinase regulatory subunit 6; WDR41, WD repeat domain 41; GATM, glycine amidinotransferase.
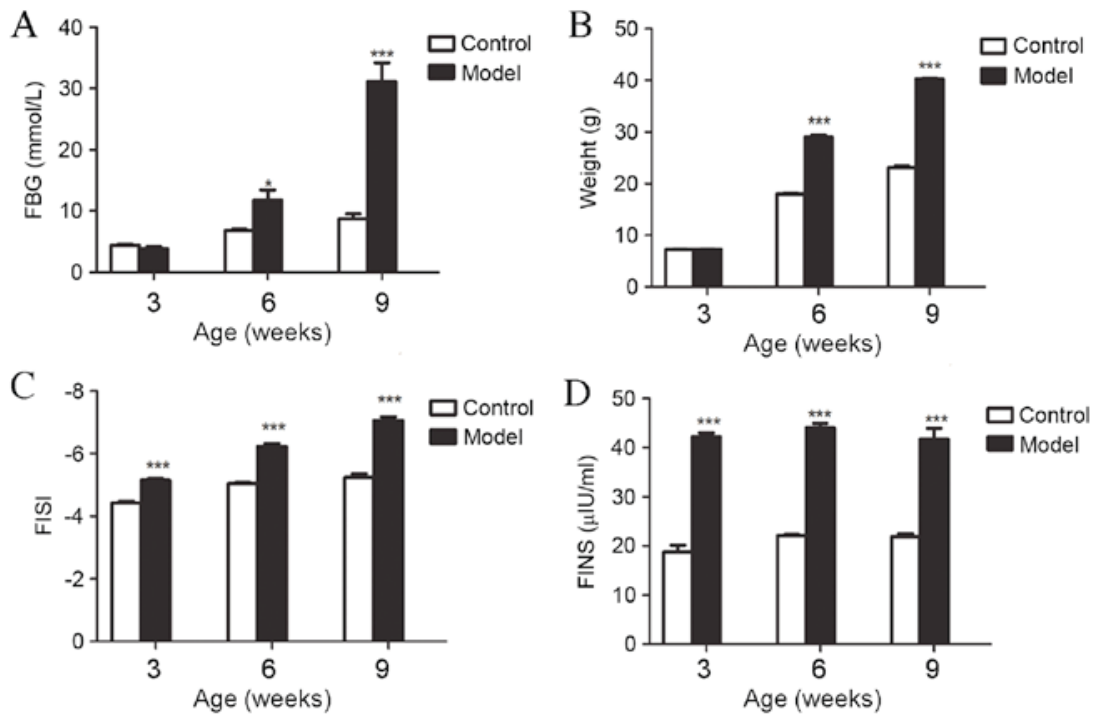

Figure 1. FBG, weight, FISI and FINS in the control and diabetic model groups for mice at three, six and nine weeks old (n=5 each). (A) Significant increases in FBG were observed in the model group at six and nine weeks old compared with their respective control groups. (B) Weights of mice in the model group were significantly greater than those in the control group for mice at six and nine weeks old, whereas weight was similar in mice at three weeks old. (C) Significant increases in FISI were observed in model groups for mice at three, six and nine weeks old compared with the control group. (D) Significant increases in FINS were observed in the model group in three, six and nine weeks old compared with the control group. All data are presented as the mean \pm standard error of the mean. ${ }^{*} \mathrm{P}<0.05$ vs. control; ${ }^{* *} \mathrm{P}<0.01$ vs. control; ${ }^{* * *} \mathrm{P}<0.001$ vs. control. FBG, fasting blood-glucose; FISI, fasting insulin sensitivity index; FINS, fasting insulin; model, BKS.Cg-m+/+Leprdb/J mice.

groups was analyzed using a Student's t-test and model groups at different time points were analyzed by one-way analysis of variance with Tukey's multiple comparison post hoc tests. Data were analyzed by SPSS 2.0 statistical software (IBM Corp., Armonk, NY, USA). $\mathrm{P}<0.05$ was considered to indicate a statistically significant difference.

\section{Results}

Physiological parameters of mice with T2D of different ages. FINS, FBG and FISI were measured in $d b / d b$ mice and controls at three, six and nine weeks old to ensure that they had developed T2D. Although FBG and weight were similar in three-week-old $d b / d b$ mice and controls they were significantly increased at six $(\mathrm{FBG}, \mathrm{P}<0.05$; weight, $\mathrm{P}<0.001)$ and nine weeks (both $\mathrm{P}<0.001$; Fig. $1 \mathrm{~A}$ and $\mathrm{B}$ ), and there was a significant reduction in FISI in $d b / d b$ mice compared with their respective controls at three, six and nine weeks old $(\mathrm{P}<0.001$; Fig. 1C). FINS in the $d b / d b$ mice group was significantly greater than in the control group at three, six and nine weeks old $(\mathrm{P}<0.001$; Fig. 1D). These physiological parameters indicated that $d b / d b$ mice had begun to develop T2D at three, six and nine weeks old.

Microarray analysis of global gene expression changes in liver tissues from mice at different ages. One of the aims of the present study was to identify patterns of gene expression that may be associated with the development of T2D. Insight into the molecular changes may ultimately guide clinical treatment of patients prior to the establishment of advanced T2D. Genes that were significantly differentially expressed in mice of different ages are shown in Table II. Global gene expression profiling was performed on RNA prepared from the liver tissue harvested from five $d b / d b$ model mice and five 

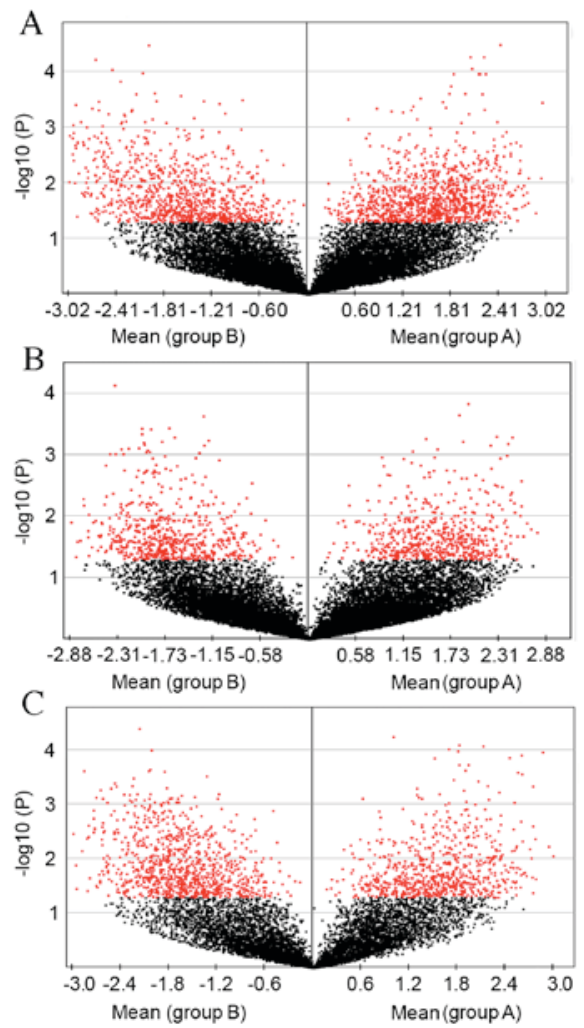

Figure 2. Globally significant genes as filtered by volcano plot between control and model groups at three, six and nine weeks old. Genome-scale differential expression levels of mRNA between the BKS.Cg-m+/+Leprdb/J model (group B) and control group (group A) at (A) three, (B) six and (C) nine weeks old were screened using a volcano plot. Each dot represents one gene. Red dots indicate genes that were significantly differentially expressed in groups $\mathrm{A}$ and $\mathrm{B}, \mathrm{P}<0.05$.

control mice for each age group (three, six and nine weeks). Results were selected according to the raw data data of the global genome microarray data of mice at each age as shown in Fig. 2A-C.

Validation of microarray data for five differentially expressed $m R N A$ in liver tissues by $R T-q P C R$. To validate the results of microarray gene expression profiling, five mRNAs with different expression patterns in the development of T2D, as identified by microarray analysis, were selected for expression verification by RT-qPCR. All expression levels were consistent with microarray predictions. mRNA expression levels of chromobox 8 ( $C B X 8)$, de-etiolated homolog 1 and damage specific DNA binding protein 1 associated 1 (DDAl), Phosphoinositide-3-kinase regulatory subunit 6 (PIK3R6) and WD repeat domain 41 (WDR41) by RT-qPCR increased significantly $(\mathrm{P}<0.05)$ and Glycine Amidinotransferase $($ GATM $)$ decreased significantly $(\mathrm{P}<0.05)$ in $d b / d b$ mice compared with controls (Fig. 3A-E). The upregulation and downregulation of these key genes in $d b / d b$ mice was markedly greater with increased age of mice (Fig. 4A-C).

\section{Discussion}

T2D is the most prevalent metabolic disease affecting various physiological functions and leading to diverse health complications (12). Although the base causes of T2D appear simple, global molecular changes must occur in response to the inability to regulate glucose. Notably, $d b / d b$ mice, which are deficient in the leptin receptor and thus leptin signaling, eventually develop hyperphagia and obesity regardless of strain background (13), which induces T2D. Such mice develop insulin resistance at an early age, as well as high FBG levels, insulin levels and FISI $(14,15)$. The results of the present study demonstrate that there were significant differences in FISI, FINS, FBG and weight between the control and model groups for mice at six and nine weeks old, with differences becoming
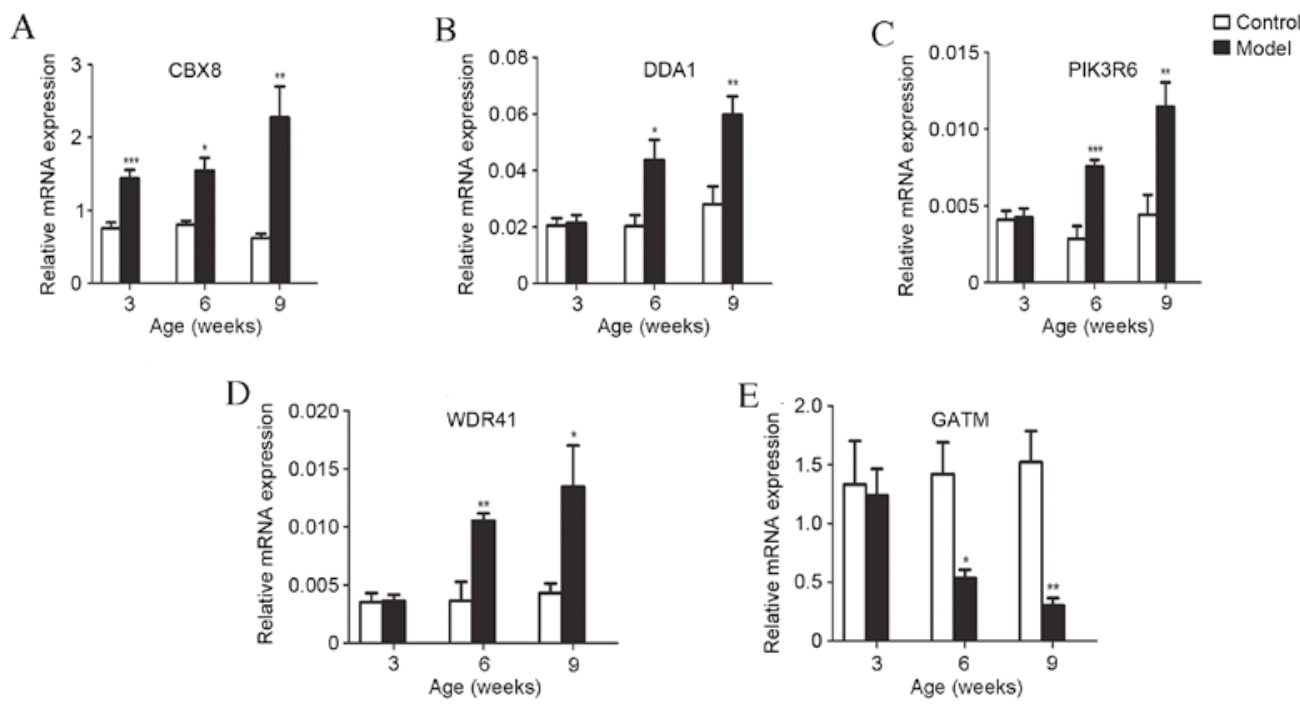

Figure 3. RT-qPCR confirmation of microarray results. The expression levels of five genes selected from the microarray data were validated via RT-qPCR. (A) Expression of $C B X 8$ increased in model mice compared with control mice at three, six and nine weeks old. Expression of (B) DDA1, (C) PIK3R6 and (D) WDR41 increased in model mice compared with their respective controls at six and nine weeks old. (E) GATM expression decreased in model mice compared with control mice at six and nine weeks old. All data are presented as the mean \pm standard error of the mean. ${ }^{*} \mathrm{P}<0.05,{ }^{* *} \mathrm{P}<0.01$ and ${ }^{* * *} \mathrm{P}<0.001$, vs. control groups. RT-qPCR, reverse transcription-quantitative polymerase chain reaction; $C B X 8$, chromobox $8 ; D D A 1$, de-etiolated homolog 1 and damage specific DNA binding protein 1 associated 1; PIK3R6, phosphoinositide-3-kinase regulatory subunit 6; WDR41, WD repeat domain 41; GATM, glycine amidinotransferase; model, BKS.Cg-m+/+Leprdb/J mice. 
A

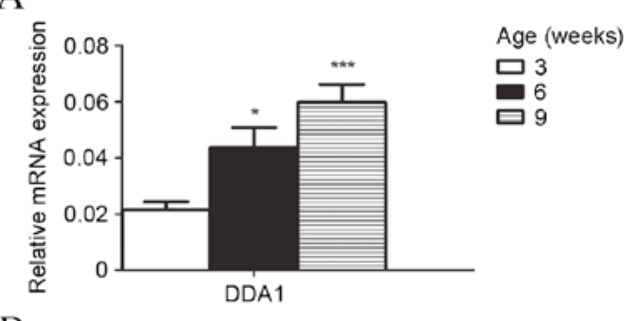

$\mathrm{B}$
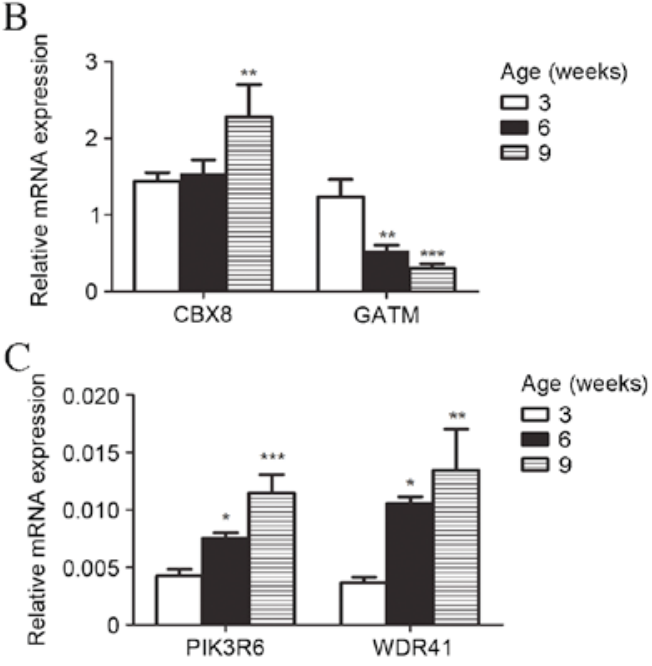

Figure 4. Expression levels of (A) DDA1, (B) $C B X 8$ and $G A T M$, and (C) PIK3R6, and WDR41 in BKS.Cg- $\mathrm{m}+/+\mathrm{Leprdb} / \mathrm{J}$ mice model mice at three, six and nine weeks old. Model groups $(\mathrm{n}=5$ each) were analyzed by one-way analysis of variance post-hoc tests. " $\mathrm{P}<0.05$ vs. 3-week old model group; ${ }^{* *} \mathrm{P}<0.01$ vs. 3 -week old model group; ${ }^{* * *} \mathrm{P}<0.001$ vs. 3 -week old model group. DDA1, de-etiolated homolog 1 and damage specific DNA binding protein 1 associated 1; CBX8, chromobox 8; GATM, glycine amidinotransferase; PIK3R6, phosphoinositide-3-kinase regulatory subunit 6; WDR41, WD repeat domain 41.

more marked with age. This demonstrates that the clinical symptoms of T2D in model rats become more apparent with age, which provides rationale for the use of $d b / d b$ mice as a reliable model for T2D.

In the present study, a number of differentially expressed mRNAs in liver tissue were detected in $d b / d b$ mice compared with normal controls. Differential gene data from mice at three, six and nine weeks old demonstrated that there were hundreds of differentially expressed genes. The five genes that were most differentially expressed were identified and screened. RT-qPCR was subsequently performed and analyzed to verify the differential expression of the five mRNAs from the microarray results. Differential expression of $C B X 8, D D A 1, P I K 3 R 6$, GATM and WDR41 in liver tissues was confirmed, which may contribute to the occurrence and development of T2D. The present study may provide useful information pertaining to the association between mRNAs and T2D development and provide rationale for further study.

To elucidate the molecular mechanisms responsible for T2D development, different ages of $d b / d b$ mice, which is a frequently used and reliable animal model, were used to identify the differentially expressed mRNAs in model and normal control liver tissues and to predict the target genes that these mRNAs regulate. This analysis demonstrated that the differentially expressed mRNAs were responsible for regulating cell proliferation, cell apoptosis and the genes responsible for hormone stimulus (16). This indicates that differential expression of these mRNAs may induce changes in liver tissue and lead to T2D development. The key genes associated with these processes include $C B X 8, D D A 1$, PIK3R6, GATM and WDR41; however, further studies are required to confirm their functions with T2D.

$C B X 8$, part of the polycomb group repressive complex 1 , belongs to the CBX protein family, which is homologous to the Drosophila polycomb protein (17) and regulates the proliferation of diploid human and mouse fibroblasts through direct binding to the INK4A-ARF locus (18). Furthermore, a previous study demonstrated that the ectopic expression of $C B X 8$ leads to cellular immortalization (19). The activation of auxin response factor and mouse double limit 2 homolog (MDM2) and subsequent protein binding weakens the E3 ubiquitin ligase function, inhibiting p53 protein degradation (20-23). Additionally, a recent study demonstrated that human abdominal adipose tissue from obese subjects and adipose tissue of mice fed a high-fat diet exhibited a reduced expression of the E3 ubiquitin ligase and exhibited IR (24). DDA1 is a $D D B 1$-binding protein that links to a negative regulator of E3 ubiquitin ligase (25). Retinoblastoma and p53 proteins cross link to protect cells against abnormal proliferation signals (26-29). The protein kinase B (Akt) pathway is considered to increase cell survival as the interaction of Akt with the phosphorylation of MDM2 in the PI3K-AKT pathway is associated with the survival, proliferation, growth and death of cells (30). It is well known that the PI3K-AKT signaling pathway is associated with the development of T2D (31). RT-qPCR analysis demonstrated an upregulation in mRNA in model liver tissues compared with normal liver tissues. This suggests that $C B X 8$ and $D D A 1$ are associated with the development of T2D.

PIK3R6 is a phosphoinositide 3-kinase (PI3K) $\gamma$ subunit (32). PI3Ks are classified as class I, II or III based on substrate binding and sequence homology. Class I PI3Ks are subdivided into $\alpha, \beta, \gamma$ and $\delta$. PI3K signaling is well known for its association with various functions, including vesicle trafficking, cell metabolism, cell growth and cell survival (33). It has previously been demonstrated that PI $3 \mathrm{~K} \gamma$ serves an essential role in the formation of sarcomas induced by a viral G-protein-coupled-receptor encoded by Kaposi's sarcoma herpes virus (34). PI $3 \mathrm{~K} \gamma$ also serves important roles in the heart (35). These studies have demonstrated that PI3K may be used as a target for the treatment of certain inflammatory and cardiac disorders (36). PIK3R6 is able to regulate the activity of PI3K, and further regulate the signal transduction of the PI3K-AKT signaling pathway (37). Phosphorylation of PI3K-AKT has been shown to improve glucose uptake and promote glucose transporter type 4 translocation from the cytoplasm to the plasma membrane, which may stimulate cellular uptake of glucose (38). Furthermore, unpublished data by the present authors demonstrated that the expression of PIK3R6 was upregulated, which may disturb the conduction of the PI3K-AKT signaling pathway and indirectly lead to the development of T2D.

GATM is an enzyme required in the rate-limiting step in the regulation of creatine biosynthesis (39). In the present study, activation of the compensatory mechanisms to increase serine, glycine and the levels of creatine may be induced by 
the differential expression of phosphoserine phosphatase, GATM and GLDC in the skeletal muscle of individuals with diabetes (40). Additionally, a recent study demonstrated that reduced GATM expression may diminish the capacity for phosphocreatine storage, and modify cellular energy storage and adenosine monophosphate-activated protein kinase (AMPK) signaling pathway conduction (41). The PI3K-AKT and AMPK pathways may be potential targets for the regulation of glucose metabolism associated with IR in patients with T2D and obesity (42). Glucose metabolism occurs primarily in the liver (43). In the present study, it was demonstrated that expression of GATM was downregulated in model liver tissues compared with normal liver tissues. This downregulation may affect the AMPK pathway in the liver, inducing glucose metabolism disorders, which may further affect the development of T2D.

WDR41 contains a WD40 domain consisting of six WD40 repeats. WD40 domains are associated with various cellular functions, including signal transduction, vesicular trafficking, cell cycle control, cell apoptosis, chromatin dynamics and DNA damage response (44-46). These functions are prominent features in proteins that mediate diverse protein-protein interactions and coordinate downstream events, including ubiquitination and histone methylation $(45,46)$. Histone methylation is a reversible process catalyzed by specific and general histone methyltransferases and demethylases, which in turn rely on metabolic coenzymes and respond to changes in energy supply and metabolic status (47). The results of the present study demonstrated that the genome-wide changes in T2D were directly associated with the specific histone modifications in the process of histone methylation (48). The $W D R 41$ gene was upregulated in $d b / d b$ mice at three, six and nine weeks of age, suggesting that WDR41 is associated with histone methylation and serves a function in the development of T2D.

Gene profiling data from the present study may illustrate the contributions of differentially expressed mRNAs to the underlying mechanisms of T2D in the mouse model; however, compared with human models, there are distinct physiological differences. In conclusion, the present study documents the potential molecular mechanisms associated with T2D in model mice. Novel genes associated with T2D have been identified, and future studies should investigate two aspects; to validate expression and functions of these key mRNAs in T2D human and mice, and to investigate how the knockout or knockin effect of these key mRNA expression levels may affect T2D development.

\section{Acknowledgements}

The authors would like to thank Dr. Wei Liu of the Key Laboratory of Myocardial Ischemia (Harbin Medical University) of the Chinese Ministry of Education for guidance and assistance for technical support. The present study was supported by grants from the National Natural Science Foundation of China (grant no. 81273650); the Chinese Ministry of Science and Technology (grant no. 2012ZX09103201-018); the Natural Science Foundation of Heilongjiang province (grant no. LC2011C03); the Harbin Science and Technology Bureau of Heilongjiang Province (grant no. 2011RFLXS024);
Heilongjiang University of Chinese Medicine 'Excellent Creative Talents Support Program' (grant no. 2012RCD19) and the Key Laboratory of Myocardial Ischemia, Harbin Medical University, Chinese Ministry of Education (grant no. KF201319).

\section{References}

1. Haslam DW and James WP: Obesity.Lancet 366: 1197-1209, 2005.

2. Langeveld M and Aerts JM: Glycosphingolipids and insulin resistance. Prog Lipid Res 48: 196-205, 2009.

3. Ai J, Wang N, Yang M, Du ZM, Zhang YC and Yang BF: Development of Wistar rat model of insulin resistance. World $\mathrm{J}$ Gastroenterol 11: 3675-3679, 2005.

4. Stoffers DA: The development of beta-cell mass: Recent progress and potential role of GLP-1. Horm Metab Res 36: 811-821, 2004.

5. Flück CE, Slotboom J, Nuoffer JM, Kreis R, Boesch C and Mullis PE: Normal hepatic glycogen storage after fasting and feeding in children and adolescents with type 1 diabetes. Pediatr Diabetes 4: 70-76, 2003

6. Kuang H, Han D, Xie J, Yan Y, Li J and Ge P: Profiling of differentially expressed microRNAs in premature ovarian failure in an animal model. Gynecol Endocrinol 30: 57-61, 2014.

7. Hummel KP, Dickie MM and Coleman DL: Diabetes, a new mutation in the mouse. Science 153: 1127-1128, 1966.

8. Yun KU, Ryu CS, Lee JY, Noh JR, Lee CH, Lee HS, Kang JS, Park SK, Kim BH and Kim SK: Hepatic metabolism of sulfur amino acids in db/db mice. Food Chem Toxicol 53: 180-186, 2013.

9. Davis RC, Castellani LW, Hosseini M, Ben-Zeev O, Mao HZ, Weinstein MM, Jung DY, Jun JY, Kim JK, Lusis AJ and Péterfy M: Early hepatic insulin resistance precedes the onset of diabetes in obese C57BLKS-db/db mice. Diabetes 59: 1616-1625, 2010.

10. Permutt MA, Wasson J and Cox N: Genetic epidemiology of diabetes. J Clin Invest 115: 1431-1439, 2005.

11. Bonnefond A, Froguel $\mathrm{P}$ and Vaxillaire $\mathrm{M}$ : The emerging genetics of type 2 diabetes. Trends Mol Med 16: 407-416, 2010.

12. Panzer C, Lauer MS, Brieke A, Blackstone E and Hoogwerf B: Association of fasting plasma glucose with heart rate recovery in healthy adults: A population-based study. Diabetes 51: 803-807, 2002.

13. Lutz TA and Woods SC: Overview of animal models of obesity. Curr Protoc Pharmacol Chapter 5: Unit5.61, 2012.

14. Lee W, Ham J, Kwon HC, Kim YK and Kim SN: Anti-diabetic effect of amorphastilbol through PPAR $\alpha / \gamma$ dual activation in $\mathrm{db} / \mathrm{db}$ mice. Biochem Biophys Res Commun 432: 73-79, 2013.

15. Puff R, Dames P, Weise M, Göke B, Seissler J, Parhofer KG and Lechner A: Reduced proliferation and a high apoptotic frequency of pancreatic beta cells contribute to genetically-determined diabetes susceptibility of db/db BKS mice. Horm Metab Res 43: 306-311, 2011.

16. Dweep H, Sticht C, Kharkar A, Pandey P and Gretz N: Parallel analysis of mRNA and microRNA microarray profiles to explore functional regulatory patterns in polycystic kidney disease: Using PKD/Mhm rat model. PLoS One 8: e53780, 2013.

17. Maertens GN, El Messaoudi-Aubert S, Racek T, Stock JK, Nicholls J, Rodriguez-Niedenführ M, Gil J and Peters G: Several distinct polycomb complexes regulate and co-localize on the INK4a tumor suppressor locus. PLoS One 4: e6380, 2009.

18. Bracken AP, Kleine-Kohlbrecher D, Dietrich N, Pasini D, Gargiulo G, Beekman C, Theilgaard-Mönch K, Minucci S, Porse BT, Marine JC, et al: The Polycomb group proteins bind throughout the INK4A-ARF locus and are disassociated in senescent cells. Genes Dev 21: 525-530, 2007.

19. Dietrich N, Bracken AP, Trinh E, Schjerling CK, Koseki H, Rappsilber J, Helin K and Hansen KH: Bypass of senescence by the polycomb group protein $\mathrm{CBX} 8$ through direct binding to the INK4A-ARF locus. EMBO J 26: 1637-1648, 2007.

20. Stott FJ, Bates S, James MC, McConnell BB, Starborg M, Brookes S, Palmero I, Ryan K, Hara E, Vousden KH and Peters G: The alternative product from the human CDKN2A locus, p14(ARF), participates in a regulatory feedback loop with p53 and MDM2. EMBO J 17: 5001-5014, 1998.

21. Kamijo T, Weber JD, Zambetti G, Zindy F, Roussel MF and Sherr CJ: Functional and physical interactions of the ARF tumor suppressor with p53 and Mdm2. Proc Natl Acad Sci USA 95: 8292-8297, 1998. 
22. Zhang Y, Xiong Y and Yarbrough WG: ARF promotes MDM2 degradation and stabilizes p53: ARF-INK4a locus deletion impairs both the $\mathrm{Rb}$ and $\mathrm{p} 53$ tumor suppression pathways. Cell 92: 725-734, 1998

23. Pomerantz J, Schreiber-Agus N, Liégeois NJ, Silverman A, Alland L, Chin L, Potes J, Chen K, Orlow I, Lee HW, et al: The Ink4a tumor suppressor gene product, p19Arf, interacts with MDM2 and neutralizes MDM2's inhibition of p53. Cell 92: 713-723, 1998

24. Yang S, Wang B, Humphries F, Hogan AE, O'Shea D and Moynagh PN: The E3 ubiquitin ligase Pellino3 protects against obesity-induced inflammation and insulin resistance. Immunity 41: 973-987, 2014.

25. Pick E, Lau OS, Tsuge T, Menon S, Tong Y, Dohmae N, Plafker SM, Deng XW and Wei N: Mammalian DET1 regulates Cul4A activity and forms stable complexes with E2 ubiquitin-conjugating enzymes. Mol Cell Biol 27: 4708-4719, 2007.

26. Bates S, Phillips AC, Clark PA, Stott F, Peters G, Ludwig RL and Vousden KH: p14ARF links the tumour suppressors RB and 553. Nature 395: 124-125, 1998

27. de Stanchina E, McCurrach ME, Zindy F, Shieh SY, Ferbeyre G, Samuelson AV, Prives C, Roussel MF, Sherr CJ and Lowe SW: E1A signaling to p53 involves the p19(ARF) tumor suppressor. Genes Dev 12: 2434-2442, 1998.

28. Zindy F, Eischen CM, Randle DH, Kamijo T, Cleveland JL, Sherr CJ and Roussel MF: Myc signaling via the ARF tumor suppressor regulates p53-dependent apoptosis and immortalization. Genes Dev 12: 2424-2433, 1998.

29. Radfar A, Unnikrishnan I, Lee HW, DePinho RA and Rosenberg N: p19(Arf) induces p53-dependent apoptosis during abelson virus-mediated pre-B cell transformation. Proc Nat Acad Sci USA 95: 13194-13199, 1998.

30. Nacerddine K, Beaudry JB, Ginjala V, Westerman B, Mattiroli F, Song JY, van der Poel H, Ponz OB, Pritchard C, Cornelissen-Steijger $\mathrm{P}$, et al: Akt-mediated phosphorylation of Bmil modulates its oncogenic potential, E3 ligase activity and DNA damage repair activity in mouse prostate cancer. J Clin Invest 122: 1920-1932, 2012.

31. Kitagishi Y, Nakanishi A, Minami A, Asai Y, Yasui M, Iwaizako A, Suzuki M, Ono Y, Ogura Y and Matsuda S: Certain diet and lifestyle may contribute to islet $\beta$-cells protection in type-2 diabetes via the modulation of cellular PI3K/AKT Pathway. Open Biochem J 8: 74-82, 2014.

32. Biethahn K, Orinska Z, Vigorito E, Goyeneche-Patino DA, Mirghomizadeh F, Föger N and Bulfone-Paus S: miRNA-155 controls mast cell activation by regulating the PI $3 \mathrm{~K} \gamma$ pathway and anaphylaxis in a mouse model. Allergy 69: 752-762,2014.

33. Engelman JA, Luo J and Cantley LC: The evolution of phosphatidylinositol 3-kinases as regulators of growth and metabolism. Nat Rev Genet 7: 606-619, 2006.

34. Martin D, Galisteo R, Molinolo AA, Wetzker R, Hirsch E and Gutkind JS: PI3K $\gamma$ mediates kaposi's sarcoma-associated herpesvirus vGPCR-induced sarcomagenesis. Cancer Cell 19: 805-813, 2011.
35. Naga Prasad SV, Laporte SA, Chamberlain D, Caron MG, Barak L and Rockman HA: Phosphoinositide 3-kinase regulates beta2-adrenergic receptor endocytosis by AP-2 recruitment to the receptor/beta-arrestin complex. J Cell Biol 158: 563-575, 2002.

36. Vadas O, Dbouk HA, Shymanets A, Perisic O, Burke JE, Abi Saab WF, Khalil BD, Harteneck C, Bresnick AR, Nürnberg B, et al: Molecular determinants of PI3K $\gamma$-mediated activation downstream of G-protein-coupled receptors (GPCRs). Proc Natl Acad Sci USA 110: 18862-18867, 2013.

37. Geering B, Cutillas PR, Nock G, Gharbi SI and Vanhaesebroeck B: Class IA phosphoinositide 3-kinases are obligate p85-p110 heterodimers. Proc Natl Acad Sci USA 104: 7809-7814, 2007.

38. Zhu S, Sun F, Li W, Cao Y, Wang C, Wang Y, Liang D, Zhang R, Zhang S, Wang $\mathrm{H}$ and Cao F: Apelin stimulates glucose uptake through the PI3K/Akt pathway and improves insulin resistance in 3T3-L1 adipocytes. Mol Cell Biochem 353: 305-313, 2011.

39. Walker JB: Creatine: Biosynthesis, regulation, and function. Adv Enzymol Relat Areas Mol Biol 50: 177-242, 1979.

40. Hansen JS, Zhao X, Irmler M, Liu X, Hoene M, Scheler M, Li Y, Beckers J, Hrabĕ de Angelis M, Häring HU, et al: Type 2 diabetes alters metabolic and transcriptional signatures of glucose and amino acid metabolism during exercise and recovery. Diabetologia 58: 1845-1854, 2015.

41. Choe CU, Nabuurs C, Stockebrand MC, Neu A, Nunes P, Morellini F, Sauter K, Schillemeit S, Hermans-Borgmeyer I, Marescau B, et al: L-arginine: Glycine amidinotransferase deficiency protects from metabolic syndrome. Hum Mol Genet 22: 110-123, 2013.

42. Sharma BR, Kim HJ and Rhyu DY: Caulerpa lentillifera extract ameliorates insulin resistance and regulates glucose metabolism in $\mathrm{C} 57 \mathrm{BL} / \mathrm{KsJ}-\mathrm{db} / \mathrm{db}$ mice via PI3K/AKT signaling pathway in myocytes. J Transl Med 13: 62, 2015.

43. Mithieux G, Gautier-Stein A, Rajas F and Zitoun C: Contribution of intestine and kidney to glucose fluxes in different nutritional states in rat. Comp Biochem Physiol B Biochem Mol Biol 143: 195-200, 2006.

44. Smith TF: Diversity of WD-repeat proteins. Subcell Biochem 48: 20-30, 2008.

45. $\mathrm{Xu} \mathrm{C}$ and Min J: Structure and function of WD40 domain proteins. Protein Cell 2: 202-214, 2011.

46. Stirnimann CU, Petsalaki E, Russell RB and Müller CW: WD40 proteins propel cellular networks. Trends Biochem Sci 35: 565-574, 2010 .

47. Teperino R, Schoonjans K and Auwerx J: Histone methyl transferases and demethylases; can they link metabolism and transcription? Cell Metab 12: 321-327, 2010.

48. Jufvas A, Sjödin S, Lundqvist K, Amin R, Vener AV and Strålfors P: Global differences in specific histone H3 methylation are associated with overweight and type 2 diabetes. Clin Epigenetics 5: 15, 2013. 